\title{
Claude Simon. Allées et venues, Actes du Colloque international de Perpignan (14-15 mars 2003), études réunies par Jean-Yves Laurichesse
}

\section{Chiara Rolla}

\section{(2) OpenEdition Journals \\ Edizione digitale \\ URL: http://journals.openedition.org/studifrancesi/33692 \\ DOI: $10.4000 /$ studifrancesi.33692 \\ ISSN: 2421-5856 \\ Editore \\ Rosenberg \& Sellier}

\section{Edizione cartacea}

Data di pubblicazione: 1 décembre 2005

Paginazione: 678

ISSN: 0039-2944

\section{Notizia bibliografica digitale}

Chiara Rolla, «Claude Simon. Allées et venues, Actes du Colloque international de Perpignan (14-15 mars 2003), études réunies par Jean-Yves Laurichesse», Studi Francesi [Online], 147 (XLX | III) | 2005, online dal 30 novembre 2015, consultato il 18 avril 2021. URL: http://journals.openedition.org/ studifrancesi/33692 ; DOI: https://doi.org/10.4000/studifrancesi.33692

Questo documento è stato generato automaticamente il 18 avril 2021.

\section{cc) $($ ) $\ominus$}

Studi Francesi è distribuita con Licenza Creative Commons Attribuzione - Non commerciale - Non opere derivate 4.0 Internazionale. 


\title{
Claude Simon. Allées et venues, Actes $\mathrm{du}$ Colloque international de Perpignan (14-15 mars 2003), études réunies par Jean-Yves Laurichesse
}

\author{
Chiara Rolla
}

\section{NOTIZIA}

Claude Simon. Allées et venues, Actes du Colloque international de Perpignan (14-15 mars 2003), études réunies par JEAN-YVES LAURICHESSE, Presses Universitaires de Perpignan, 2004, pp. 266.

1 La figura del «tramway», titolo del romanzo omonimo di Claude Simon pubblicato per le edizioni Minuit nel 2001, è il filo conduttore di questa miscellanea che raccoglie gli atti del Convegno internazionale di Perpignan tenutosi nel 2003.

2 Il volume è suddiviso in tre sezioni: la prima, "Mobiles", rileva la presenza concreta, non solo in Le Tramway ma anche in romanzi anteriori, di diverse forme di mezzi di trasporto, oltre a numerose immagini che rinviano all'idea dello spostamento e del viaggio. WOLFRAM NITSCH colloca il tram simoniano sulla scia di una modernità tracciata da Huysmans, dai fratelli Goncourt, da Proust, Aragon, Sartre, Leiris, Gracq e dimostra come esso rappresenti un punto di incontro di diverse forme sociali e allegorie della scrittura, nonostante la concretezza e la materialità che il testo gli restituisce (La ligne des espaces autres: le tramway, véhicule de l'imagination moderne, pp. 23-40).

3 JEAN-YVES LAURICHESSE segue il filo delle apparizioni intermittenti del tram, da cui si sviluppa una topologia immaginaria strutturata su un'opposizione fondamentale tra Eros e Thanatos. Il tram sarebbe dunque immagine del destino prima ancora di diventare metafora della scrittura del romanziere (À la poursuite du "fatidique tramway", pp. 41-58). SJEF HOUPPERMANS propone di leggere Le Tramway partendo dall'alternanza tra 
due posture archetipo: l'immagine dell'uomo in piedi contrapposta a quella dell'uomo sdraiato (L'Homme Couché et l'Homme Debout, pp. 59-71). La centralità narrativa, diegetica e metaforica dei mezzi di trasporto in Le Palace è la conclusione a cui giunge Manuel A. TOST PLANET (Le "récit de l'homme-fusil", du Palace: une étrange affaire de transports..., pp. 73-89).

4 La seconda sezione, "Passages", descrive l'essenza instabile dell'universo e del testo di Claude Simon, mai definitivamente fissati, ma caratterizzati da un movimento tipico delle grandi opere barocche. ANNE-LISE BLANC dimostra come la digressione, figura mobile dall'effetto transitorio, sia caratteristica di una scrittura che procede per approcci progressivi verso il suo oggetto (Digression et point de fuite. Tours, détours et déplacements dans quelques romans de Claude Simon, pp. 93-110).

5 In una prospettiva antropologica Jean DUFFY mette in luce nei romanzi di Claude Simon l'importanza dei rituali, veri e propri passaggi al tempo stesso reali e simbolici che possono comportare una separazione, una marginalizzazione o un'aggregazione (Rite, passage et liminarité dans l'ouvre de Claude Simon, pp. 111-130). Stéphanie ORACE si interessa alle due tendenze tipiche della scrittura simoniana, quella verso ciò che si muove e quella verso l'immobile. Dopo averle collegate all'opposizione tra inamovibilità della madre e nomadismo del padre, l'A. le studia all'interno del ritmo stesso della frase simoniana, fatta alternativamente di slanci e di pause (Mouvement et immobilité de Claude Simon, pp. 131-151). Un approccio mitocritico permette a Metka ZUPANI di collocare l'opera di Simon sotto il segno di Hermès, figura che rappresenta la relazione, il passaggio, ma anche, per il richiamo al dio egizio Thoth, la scrittura (Hermès psychopompe: le "comme" des palimpsestes, pp. 153-168).

La terza ed ultima sezione, "Histoires", è dedicata ai complessi intrecci tra storia personale e Storia collettiva tipici della produzione di Simon, da lui stesso definita come un'opera "à base de vécu". Alastair DUNCAN dimostra come il bipolarismo apparente dei riferimenti famigliari dissimula in realtà le «allées et venues» della scrittura simoniana (Allées et venues familiales chez Claude Simon, pp. 171-181). Pascal MOUGIN si interroga sul tema onnipresente della madre e del suo ritorno (La mère, la mère toujours recommencée, pp. 183-196), mentre Patrick LONGUET s'interessa all'infanzia e a quel sentimento legato ai ricordi che l'individuo tesse lungo tutta la vita (Une enfance dans la trame d'un vieil homme, pp. 197-210). Per Jacques ISOLERY l'immagine del cammino può diventare metafora di una scrittura e di una lettura che evitano i toni ufficiali dei grandi racconti storici o autobiografici per calcare le vie ai margini del reale (Les trottoirs de l'Histoire, pp. 211-241). Infine Didier ALEXANDRE studia l'insorgere dell'événement, vero e proprio motore della scrittura (Du "Tricheur" au "Tramway", d'un événement l'autre?, pp. 243-262). 